\title{
Characteristics of the Skin of the Female Albino Rats in Different Ages: Histological, Morphometric and Electron Microscopic Study
}

\section{Sherif Mohamed Zaki*}

Department of Anatomy, Faculty of Medicine, Cairo University, El-Kasr Al Aini Street, Cairo, Egypt

\begin{abstract}
Introduction: Ageing leads to alterations and progressive changes in the skin structures. The data regarding many structural skin changes with ageing are conflicting in both humans and rats. The most recent correlative method between ages of rat with that of the human is using the developmental phase of rat-life.

Aim: The aim of the present work was to study the characteristics of the skin structures of the female albino rats at different ages based on the different phases of the rat life. This was done through histological, morphometric and electron microscopy study.

Material and methods: Forty eight female rats were used. They were divided into six groups. The studied groups were early weaning, late weaning, pre-pubertal, adolescent, adulthood and aged-phase groups. The histological sections were stained with Haematoxylin and Eosin, Orcein and Gomori's trichrome stains. The morphometric measurements included: epidermal thickness $(\mu \mathrm{m})$, dermal thickness $(\mu \mathrm{m})$, number of hair follicles, number of sebaceous glands, elastic fibre optic density and average area of collagen fibres. Electron microscopy study was also done.
\end{abstract}

Results: The epidermal thickness increased in the adolescent group, but decreased in the pre-pubertal and adolescent groups. It became thinner and flattened in the adulthood and aged-phase groups. The epidermal cells, stratum basale, stratum spinosum and stratum granulosum were not affected by the ageing process. A relatively flattening of the dermal-epidermal junction was observed in the adulthood and aged-phase groups.

The dermal thickness decreased in the adulthood and aged-phase groups. The hair follicles reached their maturation since the early weaning period. They were deeper in their position in the weaning, pre-pubertal and adolescent groups with decease in their mean number. In the adulthood and aged-phase groups, they became shallower and occupied higher position. The collagen fibres were found in the papillary and reticular layers of the dermis. The fibres were sparse and thin in the early weaning period group. After that age, the collagen fibres in the papillary layer were parallel to the surface epithelial, while the fibres in the reticular layer were arranged in the form of bundles distributed parallel and perpendicular to the surface epithelial. The average area of collagen fibres increased in the adolescent and adulthood groups, but decreased in the aged-phase group. The optic density of the elastic fibres decreased in the pre-pubertal and adolescent groups.

Conclusion: Many structural skin changes were observed in the adulthood and aged-phase groups. The epidermis became thinner and flattened, the dermal-epidermal junction became flat, the dermal thickness decreased and the hair follicles became shallower and occupied higher position. The average area of collagen fibres increased in the adulthood group, but decreased in the aged-phase group. All these changes result in impaired wound healing and impaired the formation of scars.

\section{Keywords: Ageing; Skin; Albino rat}

\section{Introduction}

Skin ageing is a complex biological process influenced by combination of endogenous or intrinsic and exogenous or extrinsic factors. These factors lead together to cumulative structural and physiological alterations and progressive changes in each skin layer [1].

Many research works had been conducted on the skin of the human [2-5] and rats [6,7] to find the effect of ageing process on the different skin structures. There were conflicting data regarding many structural skin changes with ageing in humans [8] and in rats [6].

Many methods have been investigated to correlate the ages of rats with that of the human using the weight of the eye lens, growth of molar teeth, counting of endosteal layers in the tibia and musculoskeletal growth along with the closure and thickening of the epiphyses $[9,10]$. The most recent and accurate correlative method is the correlation of the rat age with that of the human using a particular developmental phase of rat-life. Simple correlation based on the life span of the human and rat ages is not acceptable [10].

Up to our knowledge no complete study was conducted to study peculiarity of the skin structures in different ages based on the different phases of the rat life. The use of skin age based on a particular developmental phase of rat-life is very useful as it gives us an accurate

*Corresponding author: Sherif Mohamed Zaki, MD, Anatomy department, Faculty of Medicine, Cairo University El-Kasr Al Aini Street, Cairo, Egypt, Tel: 00201111124431; E-mail: zaky.sherif@yahoo.com

Received February 19, 2015; Accepted March 09, 2015; Published March 11 2015

Citation: Zaki SM. (2015) Characteristics of the Skin of the Female Albino Rats in Different Ages: Histological, Morphometric and Electron Microscopic Study. J Cytol Histol S3:004. doi:10.4172/2157-7099.S3-004

Copyright: @ 2015 Zaki SM, et al. This is an open-access article distributed under the terms of the Creative Commons Attribution License, which permits unrestricted use, distribution, and reproduction in any medium, provided the original author and source are credited. 
correlation between the structural skin changes of rats with the structural skin changes of human.

The hypothesis of the current study was the presence of peculiarity of the skin structures of the albino rat in different ages. Therefore, the aim of the present work was to study the structures of the skin of the female albino rat at different ages based on the different phases of the rat life. This was done through histological, morphometric and electron microscopy study.

\section{Material and Methods}

Forty eight female Sprague Dawley rats were used in the current study. The animals used in this study were raised in the animal house of the Faculty of Medicine, Cairo University which has its guide lines of rules and ethics.

The animals were divided into six groups; each group consisted of 8 rats. The groups were classified according to the age of the rats. This was done under the consultation of an expert veterinarian from the animal house, Faculty of Medicine, Cairo University. The studied groups were as the following:

Early and late nursing (weaning) period groups (day 10 and day 20)

The average weaning age for the laboratory rats is 3 weeks (Baker et al.) while it is approximately 6 months (180 days) for humans (American Academy of Pediatrics, 2005).

\section{Pre-pubertal group (day 22-37)}

This is the age before the sexual maturity. The rats reach sexual maturity at approximately 38 days [11]. Humans, on the other hand, develop slowly and do not reach puberty until about the average age of 11.5 years [11].

\section{Adolescent period group (day $38-210$ ) (approximately $6^{\text {th }}$ week $-8^{\text {th }}$ month)}

The sexual maturity itself does not mark the beginning of adulthood, but rather denotes the beginning of adolescence [12]. Sexual maturity is generally defined by vaginal opening in females [6]. This period ends at approximately 7-8 months of age ( 210 days) when the skeletal growth tapers off in male and female Sprague-Dawley rats [10]. In humans, one of the last growth plates to fuse is in the scapula, which closes at about 20 years of age [10].

\section{Adulthood group (Reproductive senescence)}

The rat is no longer sexually active during this stage [10]. the average age of menopause in human women is 51 years [13] while the female rats enter menopause between the ages of 15 and 20 months (600 days) [14].

\section{Aged-phase group (Post senescence)}

Female rats live an average of 485 days after senescence while female humans live an average of 10,585 days after senescence [11].

The animals were sacrificed by a high dose of ether. The dorsal skin was obtained from each rat. Before the collection of skin samples, the dorsal skin was shaved with an electric shaver.

\section{Light microscopic study}

Part of each specimen was fixed in $10 \%$ neutral-buffered formalin. Four successive sections of $5 \mu \mathrm{m}$ width were prepared from each specimen. The sections were stained with Haematoxylin and Eosin $(\mathrm{H}$ $\& E)$, Orcein stain for elastic fibers staining, and Gomori's trichrome stain for collagen fibres staining. The prepared sections were examined and photographed using a Canon digital camera (Canon, Japan) attached to IBM computer system.

\section{Electron microscopic study}

Small pieces of each specimen were fixed in $4 \%$ glutaraldehyde then washed in phosphate buffer and post-fixed in $1 \%$ osmium tetroxide. Fixation was followed by dehydration and embedding in epoxy resins. Ultrathin sections were double-stained with uranyl acetate and lead citrate. Examination and photography of the specimens were carried out using a Jeom-1400 transmission electron microscope. The examination was done in the electron microscopy department, Faculty of Agriculture, Cairo University.

\section{Morphometric study}

The sections were examined using Leica Qwin 500 image analysis software on IBM operated computer system (Leica Microsystems, Wetzlar, Germany). The specimen preparations from each rat were subjective to quantitative studies:

\section{1- Epidermal thickness $(\mu \mathrm{m})$}

2- Dermal thickness $(\mu \mathrm{m})$

3- Number of hair follicles/field.

4- Number of Sebaceous glands/field.

5- Elastic fibre optic density: This was done by transforming the image into grey image and then masking the positive areas by blue binary colour. The parameters chosen were the number of pixels, sum of grey and mean grey. The optical density was expressed in the form of mean grey.

6- The average area of collagen fibres were measured inside a standard measuring frame of a known area. The collagen fibres were selected and masked by blue binary colour. Then the area of the blue binary colour was measured and expressed as average area in relation to the area of the standard measuring frame.

The data were collected and studied using SPSS 20 statistical program. The mean and standard deviation (SD) were calculated for all variables. Analysis of variance (one way ANOVA) followed by post hoc Bonferroni test was performed to compare between the studied groups. Linear regression analysis of the effect of the age on the skin variables was done. $\mathrm{P}$ values $<0.05$ were considered statistically significant.

\section{Results}

\section{Results of $\mathrm{H}$ and $\mathrm{E}$ stained sections}

The H \& E-stained sections showed the epidermis and dermis of the rats at different ages. The epidermis gradually increased in thickness in the weaning, pre-pubertal and adolescent groups, but it became thinner and flattened in the adulthood and aged-phase groups (Figure 1a-1i).

The cells of the stratum corneum were clearly seen in the weaning, pre-pubertal and adolescent groups, but they were hardly seen using $\mathrm{H}$ $\& \mathrm{E}$ in the adulthood and aged-phase groups (Figure 1a-1i). The cells of stratum basale, stratum spinosum and keratohyalin granules of stratum granulosum were identified since the early weaning period (Figure 1b).

A relatively flattening of the dermal-epidermal junction was observed in the adulthood and were seen since the early weaning 
period (Figure 1b). Although the hair follicles occupied the whole thickness of the dermis, they were mainly deeper in their position in the weaning, pre-pubertal and adolescent groups. At the adulthood and aged-phase groups, the hair follicles became shallower and occupied higher position in the dermis (Figure 1a-1i). The weaning and prepubertal groups had a great number of hair follicles (Figure 1a-1d). A decline in the number of follicles was observed at the adolescent group (Figure 1e-1f). A further decline in the follicle numbers accompanied with some atrophy were observed at the adulthood and aged-phase groups (Figure 1g-1i).

The sebaceous glands changes were remarkably similar to the hair follicles changes concerning the number and depth at the different ages. No obvious morphological changes were observed in the glands at the adulthood and aged-phase groups (Figure 1a-1i).

The hypodermis was underdeveloped in the early weaning group with absence of the fat cells (Figure 1a). The hypodermis became well developed with the presence of the fat cells in the late weaning, prepubertal and adolescent groups (Figure 1c, 1d and 1f). Finally, the thickness of hypodermis decreased at the adulthood and aged-phase groups (Figure 1g-1i).

A layer of underdeveloped skeletal muscle layer beneath the hypodermis was observed in the early weaning period group (Figure 1a). This muscle layer became well develop with the advance of age (Figure 1c, d, f, g, i).

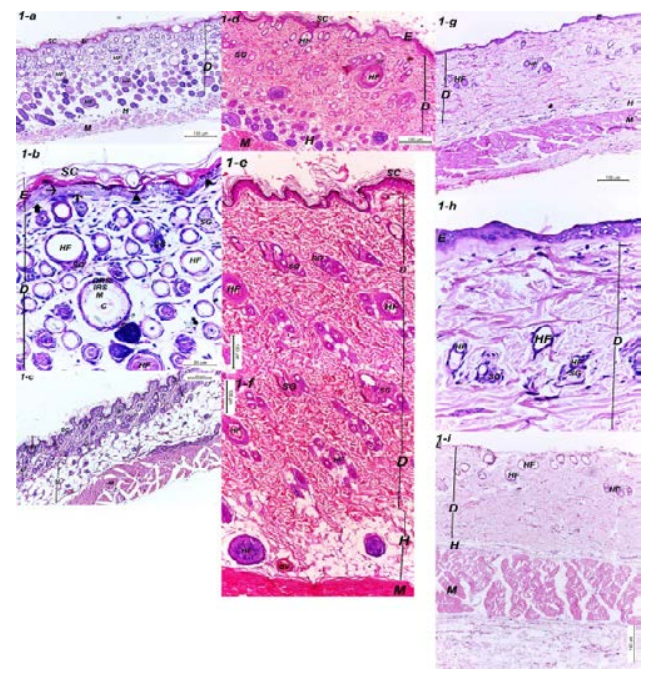

Figure 1: Skin of the different age groups stained with H\&E stain showing the stratum corneum (SC) of the epidermis (E), hair follicles (HF) within the dermal layer $(D)$ and a layer of skeletal muscle (M) beneath the skin. Note: hair follicles (HF) and fat sells $\left(^{*}\right)$ within the hypodermis $(H)$. (a) The skin of a ten day old rat. Note absence of the fat cells of the hypodermis (H\&E 100X). (1b) Higher magnification of the previous figure showing the stratum corneum (SC), cells of the stratum basale (thick arrow), cells of stratum spinosum (thin arrows) and keratohyalin granules (arrowheads) of the stratum granulosum of the epidermis. Cortex (C), medulla (M), outer cortex sheath (ORS) and inner cortex sheath (IRS) of the hair follicles (HF) $(H \& E$ 400X). (c) the skin of a twenty day old rat. (H\&E 100X). (e) the skin of a two month rat. (H\&E 100X). (E and f) the skin of a six month old rat (H\&E 100X). (g) the skin of a one year old rat. Note decrease number of hair follicles which occupied a higher position in the dermis (H\&E 100X). (h) Higher magnification of the previous figure showing atrophy of the hair follicles and absence of the layers of the stratum corneum (H\&E 400X). (i) the skin of a two year old rat where the epidermis is thin and flattened. Also, the hair follicles decreased and occupied a higher position in the dermis (H\&E 100X).

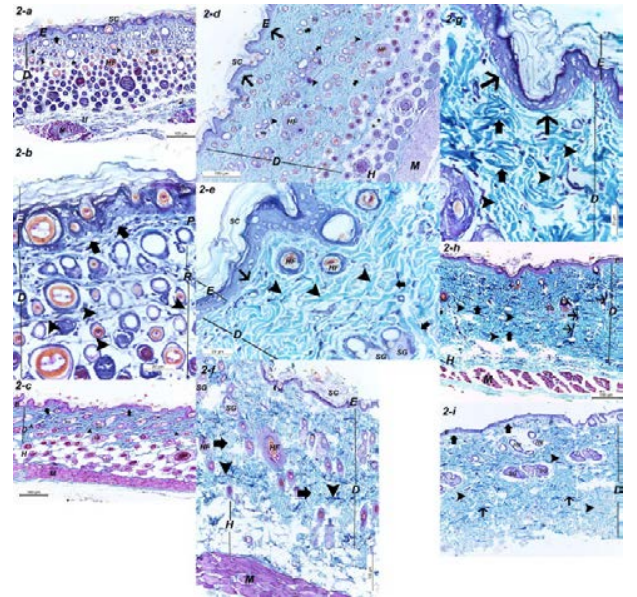

Figure 2: Skin of the different age groups stained with Gomori's trichrome stain showing the stratum corneum (SC) of the epidermis (E), dermis (D), hypodermis $(\mathrm{H})$, hair follicles (HF), sebaceous glands (SG) and a layer of skeletal muscle (M) beneath the hypodermis. Note and fat sells $\left.{ }^{*}\right)$. (a) the skin of a ten-day old rat. The collagen fibres in the papillary layer (arrow) and reticular layer (arrowheads) were sparse (Gomori's trichrome stain 100X). (b) Higher magnification of the previous figure (Gomori's trichrome stain 400X). (c) the skin of a twenty day old rat. The collagen fibres in the papillary layer (arrows) and reticular layer (arrowheads) distributed parallel to the epithelial surface thick and were regularly arranged (Gomori's trichrome stain 100X). (d) the skin of a two month old rat. The collagen fibres in the papillary layer (long arrows) were parallel to the epithelial surface, while that of the reticular layer were arranged in the form of bundles. These bundles were distributed parallel (arrowheads) and perpendicular (short arrows) to the surface epithelial (Gomori's trichrome stain 100X). (e) Higher magnification of the previous figure (Gomori's trichrome stain 400X). (f) the skin of a six month old rat. The collagen fibres in the reticular layer were arranged in thick bundles (arrowheads) parallel to the surface epithelial and thin bundles (arrows) perpendicular to the surface epithelial. (Gomori's trichrome stain 100X). (g) Higher magnification of the previous figure (Gomori's trichrome stain 400X). (h) the skin of a one year old rat. The collagen fibres in the papillary layer $\left({ }^{*}\right)$ were thin and parallel to the epithelial surface. The collagen fibres in the reticular layer were arranged in thick bundles (thick arrows) parallel to the surface epithelial. Two forms of bundles perpendicular to the surface epithelial were found; thick bundles (thin arrows) and thin bundles (arrowheads). (Gomori's trichrome stain 100X). (i) the skin a two year old rat. The collagen fibres in the papillary layer (thick arrows) were very thin and parallel to the epithelial surface. The collagen fibres in the reticular layer were arranged in thick bundles (thin arrows) parallel and thin bundles (arrowheads) perpendicular to the surface epithelial. Note atrophy of the hair follicles and absence of the layers of the stratum corneum (Gomori's trichrome stain 100X).

\section{Results of Gomori’s trichrome-stained sections}

\section{Results of Orcein-stained sections}

Orcein stain was used to identify the density and the distribution of the elastic fibres in the papillary and reticular layers of the dermis (Figure 3).

\section{Results of electron micrograph sections}

The stratum basale cells were identified at all ages (Figures 4-8). At the early weaning group the basal cells were seen attached to each other's via desmosomes and to the basal lamina by hemidesmosomes (Figure 4a, 7a, 7b and 8a-8c). Narrow intercellular spaces in-between the cells were also seen (Figure 4a). At the adulthood and aged-phase groups bundles of tonofilaments were clearly observed extending across the cells in many directions. In addition, the basal laminae upon which the basal cells resting were well developed (Figure $7 \mathrm{a}, 7 \mathrm{~b}$ and 8a). Cytoplasmic vacuolations in the basal cells were identified at the adulthood group (Figure 7a). 
Citation: Zaki SM (2015) Characteristics of the Skin of the Female Albino Rats in Different Ages: Histological, Morphometric and Electron Microscopic Study. J Cytol Histol S3:004. doi:10.4172/2157-7099.S3-004

The cells of stratum spinosum were also identified at all ages (Figure $4 \mathrm{a}, 4 \mathrm{~b}, 7 \mathrm{~b}$ and $8 \mathrm{c}$ ). The cells are attached to each other's via desmosomes (Figure 4a). At the aged-phase group bundles of tonofilaments were observed extending across the cells in many directions (Figure 8c).

The cells of stratum granulosum were also identified at all ages (Figure $4 \mathrm{~b}, 7 \mathrm{~b}, 7 \mathrm{c}$ and $8 \mathrm{~d}$ ). These cells contain numerous keratohyalin granules (Figure $4 \mathrm{~b}, 7 \mathrm{c}$ and $8 \mathrm{~d}$ ). The cell borders lost the spiny cytoplasmic processes (Figure 4b). The cells of the stratum corneum were also identified at all ages. They were filled with electron-dense material at all ages (Figure $4 c, 6 b$ and $8 \mathrm{e}$ ).

A relative increase in collagen fibres was observed at the late weaning group (Figure $5 \mathrm{a}$ and $5 \mathrm{~b}$ ) when compared with that of the early weaning group (Figure 4a). The collagen fibres increased in the prepubertal and adulthood groups (Figure $6 \mathrm{a}, 6 \mathrm{c}$ and $7 \mathrm{~d}$ ) with their fibres running in different directions. A relative decrease in the collagen fibres was observed at the aged-phase group (Figure $8 \mathrm{a}$ and $8 \mathrm{~b}$ ).

Normal dermal mast cells filled with granules and fibroblast cells were observed at all ages (Figure $5 \mathrm{~b}$ and $7 \mathrm{~d}$ ).

\section{Morphometric results}

The mean and standard deviation of the variables in the different age groups were displayed in Tables 1 and 2.

Regression analysis of the age versus the data of skin variables in the different age groups were displayed in Table 2. A significant reduction in the optic density of elastic fibres, number of hair follicles and number of sebaceous glands in correlation to age was noted. The correlation analysis showed negative linear effect of the age on the optic density of elastic fibres $\left(R^{2}=0.80, P=0.000\right)$, number of hair follicles $\left(R^{2}=0.60\right.$, $\mathrm{P}=0.000)$ and number of sebaceous glands $\left(\mathrm{R}^{2}=0.32, \mathrm{P}=0.001\right)$ (Table 3 , Figure 9).

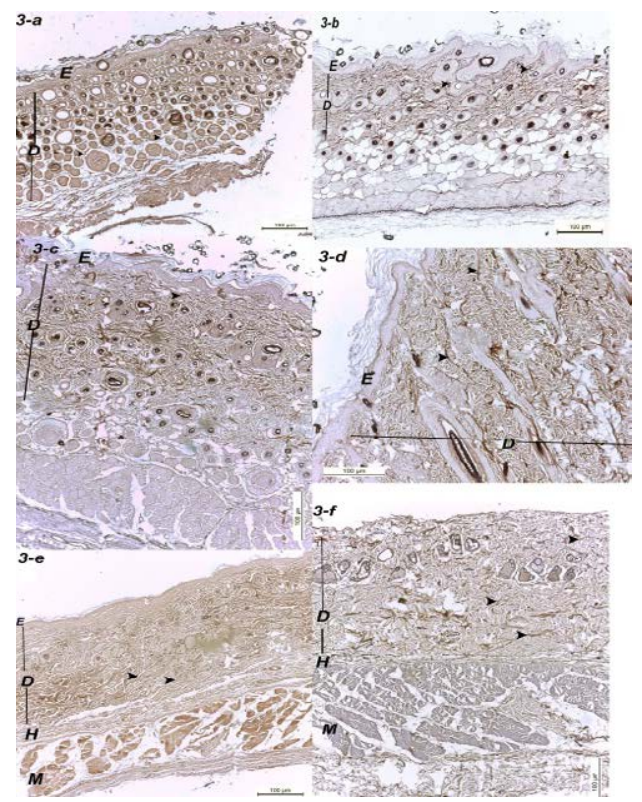

Figure 3: Skin of the different age groups stained with Orcein stain showing the distribution of the elastic fibres (arrowheads). Note epidermis (E) and dermis (D). (a) A ten day old rat (100X). (b) A twenty day old rat (100X). (c) A two month old rat. (d) A six month old rat. (e) A one year old rat (100X). (f) A two year old rat (100X). (g) Optic density of elastic fibres (blue colour) of a two year old rat (200X).
A significant increase in the mean area of collagen fibres of the adolescent and adulthood groups was observed when compared with their similarity of the weaning groups. In the opposite side, a significant decrease in the mean area of collagen fibres at the aged-phase group when compared with their similarity of the adolescent and adulthood groups (Table 4 and Figure 10).

A significant decrease in the mean of the optic density of elastic fibres of the pre-pubertal group was observed when compared with that of the weaning groups. A further significant decrease in the mean of the optic density of elastic fibres was noted at the adolescent when compared with that of the previous groups. The adulthood and agedphase groups showed non-significant decrease in the optic density of elastic fibres when compared with that of the pre-pubertal and

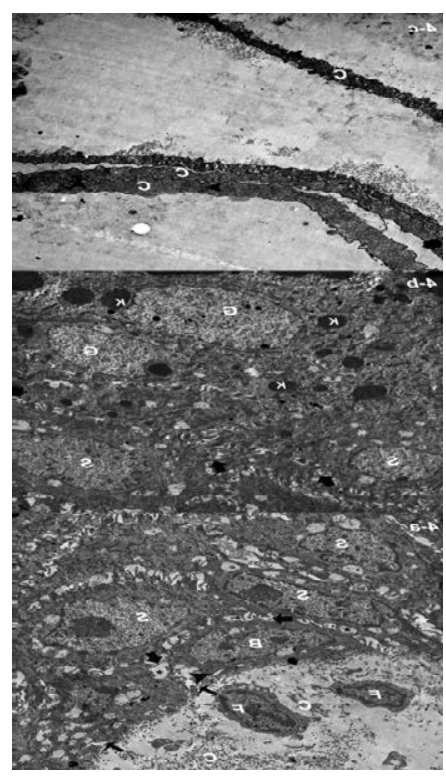

Figure 4: Electron micrograph of the skin a ten day old rat showing: (a) Too little collagen fibres $(C)$, fibroblast $(F)$, cells of stratum spinosum (S) and cells of stratum basale (B). The basal cells are attached to each other's by desmosomes (thick arrows) and to the basal lamina (thin arrows) by hemidesmosomes (arrowhead). Note narrow intercellular spaces $\left(^{*}\right)$ inbetween the stratum basale cells (X 4000). (b) Cells of stratum spinosum $(S)$ with narrow intercellular spaces $\left(^{*}\right)$ in-betweens. The cells are attached to each other's by desmosomes (arrows). A stratum granulosum cells (G) contains keratohyalin granules $(K)(x 4000)$. (c) The stratum corneum cells (C) filled with electron-dense materials (arrowheads).

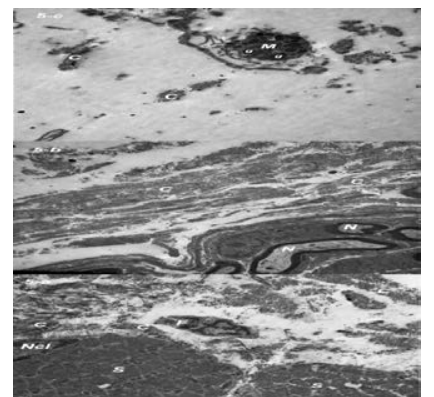

Figure 5: Electron micrograph of a twenty day rat's skin showing: (a) Collagen fibres longitudinally and cross-sectioned (C), fibroblast (F), skeletal muscle (S) and its nucleus (Ncl) (X 4000). (b) Collagen fibres (C) and myelinated derm nerves (N) (X 2500). (c) Collagen fibres (C) and normal dermal mast cell (M) filled with granules (g) (X 4000). 


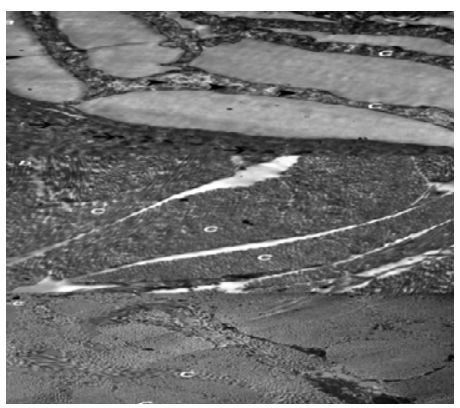

Figure 6: Electron micrograph of rats' skin showing: (a) The stratum corneum cells $(\mathrm{C})$ filled with electron-dense materials (arrowheads) of a two month rat's skin. Note the keratohyalin granules (arrows) (4000X). (b) A well-developed collagen fibres (C) of a two month rat's skin (5000X). (c) Collagen fibres (C) and elastic fibres (e) of a six month rat's skin (3000X).

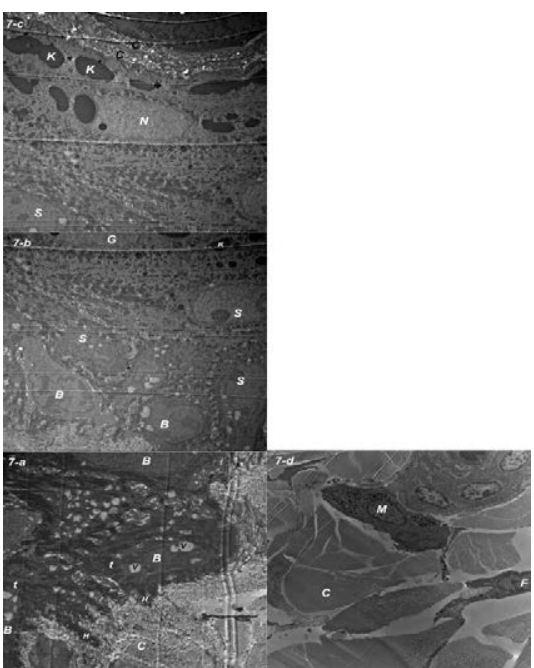

Figure 7: Electron micrograph of one year rats' skin showing: (a) The stratum basale cells $(B)$ with their nuclei and tonofilaments $(t)$. The cells are attached to each other's by desmosomes $\left(^{*}\right)$ and are attached via hemidesmosomes $(\mathrm{H})$ to the well-developed basal lamina (arrowheads). Note collagen fibres $(\mathrm{C})$ and vacuolations $(\mathrm{V})$ of the cytoplasm of the basal cells $(6000 \mathrm{X})$. (b) Cells of stratum spinosum $(S)$ with narrow intercellular spaces $\left(^{*}\right)$ in-between. A cell of stratum granulosum $(\mathrm{G})$ contains keratohyalin granules $(\mathrm{K})$. Note cells of stratum basale (B) (4000X). (c) A cell of stratum spinosum (S), Nucleus (N) o stratum granulosum cell and keratohyalin granules $(K)$. Note the layers $(C)$ of the stratum corneum cells (4000X). (d) Collagen fibres (C), fibroblast cell $(F)$ and normal dermal mast cell (M) filled with granules (2500X).

adolescent groups (Table 4, Figures 11 and 12).

Concerning the mean of the epidermal thickness, a non-significant increase was observed at the late weaning and pre-pubertal groups when compared with that of the early weaning group. Then with the advance of the age, a significant increase in the mean of the epidermal thickness was observed in the adolescent group. Finally, a significant decrease in the mean of the epidermal thickness was observed at the adulthood and aged-phase groups (Table 4).

Non-significant increase in the mean of the dermal thickness at the late weaning group was noted when compared with that of the early weaning group. This increase became significant at the pre-pubertal and adolescent age compared to the weaning groups. A significant decrease in the mean of the dermal thickness of the adulthood and aged-phase

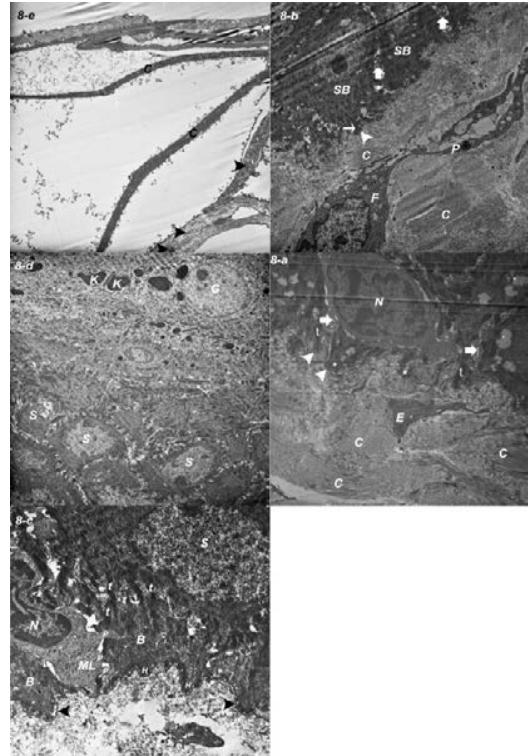

Figure 8: Electron micrograph of two year rats' skin showing: (a) well developed collagen fibres (C) and elastic fibres (E). The nucleus $(N)$ of the basal cell fills the major part of the cell and the cells are attached to their neighbors by desmosomes (thick arrow) and to the well-developed basal lamina (arrowheads) by hemidesmosomes $\left({ }^{*}\right)$. Note the presence of bundles of tonofilaments $(t)$ in the stratum basale cells $(6000 \mathrm{X})$. (b) well developed collagen fibres $(C)$, fibroblast $(F)$ with its process and the stratum basale cells (SB) which are attached to their neighbors by desmosomes (thick arrows) and to the well-developed basal lamina (arrowheads) by hemidesmosomes (thin arrow). Note intercellular spaces $\left(^{*}\right)$ in-between the stratum basale cells (4000X). (c) A melanocyte (MN) with its nucleus $(\mathrm{N})$ and its dendritic processes $(\mathrm{P})$ which extend between the basal cells. Note stratum basale cells $(B)$ with their hemidesmosomes $(H)$. Tonofilaments $(t)$ were seen in stratum basale and stratum spinosum cells. Note the well-developed basal lamina (arrowheads) and the nucleus of a stratum spinosum cell (S) (6000X). (d) Cells of stratum spinosum (S) and stratum granulosum $(G)$ with their keratohyalin granules $(K)$ (2500X). (e) The stratum corneum cells (C) filled with electron-dense materials (arrowheads) (3000X)

groups was noted when compared with their similarity of the prepubertal and adolescent groups (Table 5).

A significant decrease in the mean number of the hair follicles was observed in the late weaning and pre-pubertal groups when compared with that of the early weaning group. A further significant decrease in the mean number of the hair follicles was observed in the adolescent group when compared with that of the previous 3 groups. A nonsignificant change in the mean number of the hair follicles was noted in the adulthood and aged-phase groups when compared with that of the adolescent group (Table 5).

Late weaning, pre-pubertal and adolescent groups the adulthood and aged-phase groups

The mean number of the sebaceous glands was significantly high at the early weaning group when compared with that of the other groups. A non-significant change in the mean number of the sebaceous glands was identified in all other groups when compared with each other (Table 5).

\section{Discussion}

The skin is composed of epidermis, dermis and subcutaneous tissue that interconnect anatomically. The dermis is an integrated system of fibrous and amorphous connective tissue that accommodates nerve 
Citation: Zaki SM (2015) Characteristics of the Skin of the Female Albino Rats in Different Ages: Histological, Morphometric and Electron Microscopic Study. J Cytol Histol S3:004. doi:10.4172/2157-7099.S3-004

Page 6 of 4

\begin{tabular}{|c|c|c|c|}
\hline & $\begin{array}{c}\text { Correlating of the human age with the age } \\
\text { of the rat* }\end{array}$ & $\begin{array}{l}\text { The age of the at the end } \\
\text { of the phase }\end{array}$ & Human age at the end of the phase \\
\hline Entire life span & 13.2 rat days $=1$ human year & & \\
\hline Weaning (nursing)period & 42.4 rat days $=1$ human year & $\begin{array}{c}3 \text { weeks } \\
\text { Day } 21(\mathrm{P} 21)\end{array}$ & $\begin{array}{l}6 \text { months } \\
\text { (180 days) }\end{array}$ \\
\hline Pre-pubertal period & 3.3 rat days $=1$ human year & Approximately 6 weeks Day 37 (P37) & $\begin{array}{c}11.5 \text { years } \\
\text { (4198 days) }\end{array}$ \\
\hline Adolescent period & 10.5 rat days $=1$ human year & $\begin{array}{c}\text { Approximately } \\
\text { 7-8 months (Day 210) }\end{array}$ & $\begin{array}{c}20 \text { years } \\
\text { (7300 days) }\end{array}$ \\
\hline $\begin{array}{l}\text { Adulthood (Reproductive } \\
\text { senescence) }\end{array}$ & 11.8 rat days $=1$ human year & $\begin{array}{l}\text { 15- } 20 \text { months } \\
\text { (600 days) }\end{array}$ & $\begin{array}{c}51 \text { years } \\
\text { (18615 days) }\end{array}$ \\
\hline Aged-phase (Post senescence) & 17.1 rat days $=1$ human year & $\begin{array}{l}\text { Female rats live an average of } 485 \text { days after } \\
\text { senescence }\end{array}$ & $\begin{array}{l}\text { Female humans live an average of } \\
10,585 \text { days after senescence }\end{array}$ \\
\hline
\end{tabular}

$\mathrm{P}=$ postnatal

Table 1: Correlating of the human age with the age of the rat.

\begin{tabular}{|c|c|c|c|c|c|c|}
\hline & Early weaning & Late weaning & Pre-pubertal & Adolescent & Adulthood & Aged-phase \\
\hline & Mean $\pm S D$ & Mean \pm SD & Mean \pm SD & Mean \pm SD & Mean \pm SD & Mean \pm SD \\
\hline Average area of collagen fibres & $7.75 \pm 2.14$ & $8.0 \pm 4.00$ & & $23.76 \pm 4.63$ & $20.24 \pm 6.37$ & $9.84 \pm 2.91$ \\
\hline Optic density of elastic fibres & $64.61 \pm 0.23$ & $64.71 \pm 0.34$ & $49.12 \pm 0.49$ & $44.06 \pm 0.86$ & $43.63 \pm 0.75$ & $43.74 \pm 0.41$ \\
\hline Epidermal thickness $(\mu \mathrm{m})$ & $48.02 \pm 8.17$ & $74.44 \pm 5.35$ & $76.02 \pm 30.94$ & $167.10 \pm 20.88$ & $28.56 \pm 9.07$ & $18.66 \pm 4.39$ \\
\hline Dermal thickness $(\mu \mathrm{m})$ & $417.9 \pm 47.0$ & $479.6 \pm 35.4$ & $1018.3 \pm 32.8$ & $1599.3 \pm 107.4$ & $729.03 \pm 73.07$ & $839.1 \pm 37.2$ \\
\hline Number of hair follicles/field & $71.80 \pm 4.02$ & $17.20 \pm 0.44$ & $26.80 \pm 4.49$ & $7.60 \pm 1.67$ & $8.20 \pm 0.83$ & $8.00 \pm 1.22$ \\
\hline $\begin{array}{c}\text { Number of sebaceous glands/ } \\
\text { field }\end{array}$ & $8.60 \pm 1.34$ & $3.20 \pm 0.44$ & $4.40 \pm 1.34$ & $4.20 \pm 0.83$ & $3.40 \pm 0.54$ & $3.20 \pm 2.58$ \\
\hline
\end{tabular}

SD: Standard Deviation

Table 2: Mean and standard deviation of the skin measurements in the different studied groups

\begin{tabular}{|c|c|c|c|c|c|c|}
\hline & & $\mathbf{R}^{2}$ & Std. error of the estimate & P Value & Coefficients $\beta$ & Slope of the age group \\
\hline \multirow{6}{*}{ Age } & Average area of Collagen fibres & 0.11 & 7.57 & 0.07 & 9.35 & 1.5 \\
\hline & Optic density of elastic fibres & 0.80 & 4.33 & $0.000^{*}$ & 68.91 & -4.93 \\
\hline & Epidermal thickness $(\mu \mathrm{m})$ & 0.03 & 51.85 & 0.3 & 88.13 & -5.52 \\
\hline & Dermal thickness $(\mu \mathrm{m})$ & 0.01 & 407.53 & 0.4 & 799.3 & 6.3 \\
\hline & Number of hair follicles/field & 0.60 & 14.87 & $0.000^{*}$ & 59.78 & -10.43 \\
\hline & $\begin{array}{c}\text { Number of sebaceous glands/ } \\
\text { field }\end{array}$ & 0.32 & 1.91 & $0.001^{*}$ & 7.16 & -0.76 \\
\hline
\end{tabular}

$\mathrm{R}^{2}$ : R square; Std. error: Standard error; *statistically significant

Table 3: Regression analysis of the age (independent variable) versus the data of skin structures (dependent variables).

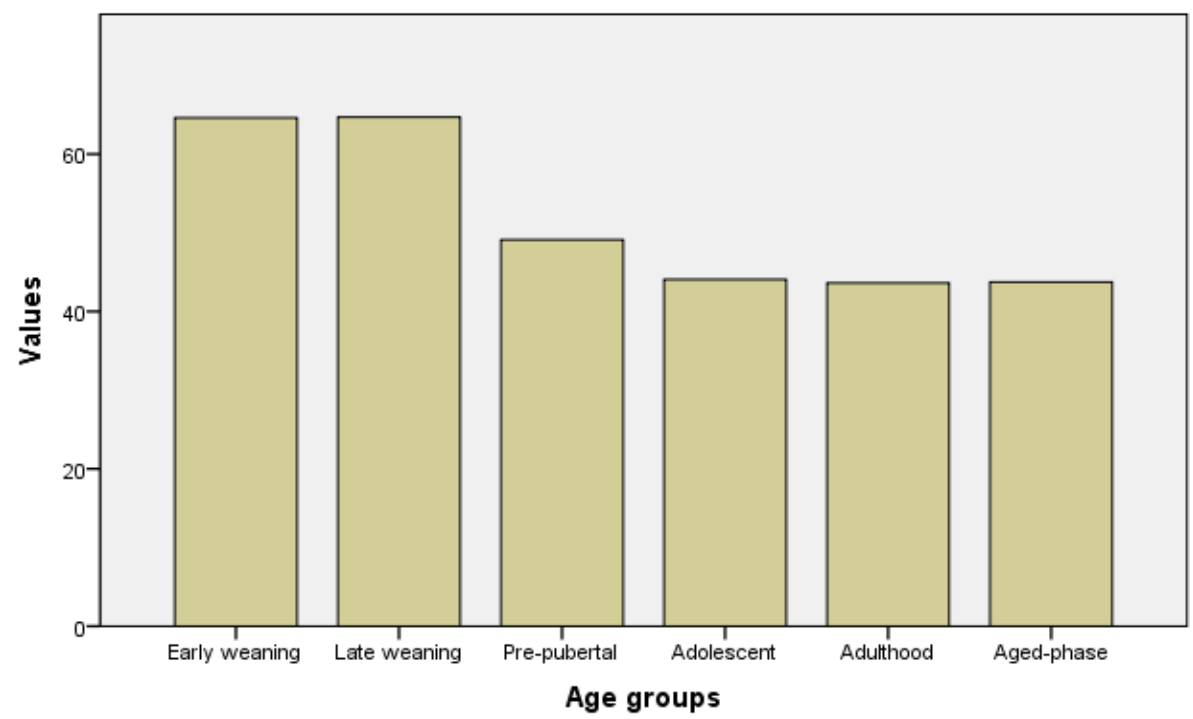

Figure 9: The mean area of the optical density of elastic fibres collagen of the different studied groups 
Citation: Zaki SM (2015) Characteristics of the Skin of the Female Albino Rats in Different Ages: Histological, Morphometric and Electron Microscopic Study. J Cytol Histol S3:004. doi:10.4172/2157-7099.S3-004

Page 7 of 4

\begin{tabular}{|c|c|c|c|c|c|c|c|}
\hline \multirow{2}{*}{ (I) Age group } & \multirow{2}{*}{ (J) Age group } & \multicolumn{2}{|c|}{$\begin{array}{l}\text { Epidermal thickness } \\
(\mu \mathrm{m})\end{array}$} & \multicolumn{2}{|l|}{$\begin{array}{l}\text { Dermal thickness } \\
(\mu \mathrm{m})\end{array}$} & \multicolumn{2}{|l|}{$\begin{array}{l}\text { Number of hair } \\
\text { follicles/field }\end{array}$} \\
\hline & & $\begin{array}{l}\text { Mean Difference } \\
(\mathrm{I}-\mathrm{J})\end{array}$ & $\begin{array}{l}\mathrm{P} \\
\text { value }\end{array}$ & $\begin{array}{l}\text { Mean Difference } \\
(I-J)\end{array}$ & $P$ value & $\begin{array}{l}\text { Mean Difference } \\
(I-J)\end{array}$ & $P$ value \\
\hline \multirow{5}{*}{ Early weaning } & Late weaning & -26.42 & 0.2 & -61.67 & 1 & 54.60 & $0.000^{*}$ \\
\hline & Pre-pubertal & -27.99 & 0.1 & -600.39 & $0.000^{*}$ & 45.00 & $0.000^{*}$ \\
\hline & Adolescent & -119.12 & $0.000^{*}$ & -1181.32 & $0.000^{*}$ & 64.20 & $0.000^{*}$ \\
\hline & Adulthood & 19.45 & 1 & $-311.03^{\star}$ & $0.000^{*}$ & 63.60 & $0.000^{*}$ \\
\hline & $2^{\text {nd }}$ year & 29.35 & 0.1 & -421.12 & $0.000^{*}$ & 63.80 & $0.000^{*}$ \\
\hline \multirow{5}{*}{$\begin{array}{l}\text { Late } \\
\text { weaning }\end{array}$} & Early weaning & 26.42 & 0.2 & 61.67 & 1 & -54.60 & $0.000^{*}$ \\
\hline & Pre-pubertal & -1.57 & 1 & -538.72 & $0.000^{*}$ & -9.60 & $0.000^{*}$ \\
\hline & Adolescent & -92.69 & $0.000^{*}$ & -1119.65 & $0.000^{*}$ & 9.60 & $0.000^{*}$ \\
\hline & Adulthood & 45.88 & $0.002^{*}$ & -249.36 & $0.000^{*}$ & 9.00 & $0.000^{*}$ \\
\hline & Aged-phase & 55.77 & $0.000^{*}$ & -359.44 & $0.000^{*}$ & 9.20 & $0.000^{*}$ \\
\hline \multirow{5}{*}{ Pre-pubertal } & Early weaning & 27.99 & 0.1 & 600.39 & $0.000^{*}$ & -45.00 & $0.000^{*}$ \\
\hline & Late weaning & 1.57 & 1 & 1119.65 & $0.000^{*}$ & -9.60 & $0.000^{*}$ \\
\hline & Adolescent & -91.12 & $0.000^{*}$ & -580.93 & $0.000^{*}$ & 19.20 & $0.000^{*}$ \\
\hline & Adulthood & 47.45 & $0.002^{*}$ & 289.36 & $0.000^{*}$ & 18.60 & $0.000^{*}$ \\
\hline & Aged-phase & 57.35 & $0.000^{*}$ & 179.276 & $0.001^{*}$ & 18.80 & $0.000^{*}$ \\
\hline \multirow{6}{*}{ Adolescent } & Early weaning & 119.12 & $0.000^{*}$ & 1181.32 & $0.000^{*}$ & -64.20 & $0.000^{*}$ \\
\hline & Late weaning & 92.69 & $0.000^{*}$ & 1119.65 & $0.000^{*}$ & -9.60 & $0.000^{*}$ \\
\hline & Pre-pubertal & 91.12 & $0.000^{*}$ & 580.93 & $0.000^{*}$ & -19.20 & $0.000^{*}$ \\
\hline & Adulthood & 138.57 & $0.000^{*}$ & 870.29 & $0.000^{*}$ & -0.60 & 1 \\
\hline & Aged-phase & 148.47 & $0.000^{*}$ & 760.20 & $0.000^{*}$ & -0.40 & 1 \\
\hline & Early weaning & -19.45 & 1 & $311.03^{*}$ & $0.000^{*}$ & -63.60 & $0.000^{*}$ \\
\hline \multirow{5}{*}{ Adulthood } & Late weaning & -45.88 & $0.002^{*}$ & 249.36 & $0.000^{*}$ & -9.00 & $0.000^{*}$ \\
\hline & Pre-pubertal & -47.45 & $0.002^{*}$ & -289.36 & $0.000^{*}$ & -18.60 & $0.000^{*}$ \\
\hline & Adolescent & -138.57 & $0.000^{*}$ & -870.29 & $0.000^{*}$ & 0.60 & 1 \\
\hline & Aged-phase & 9.89 & 1 & -110.08 & 0.1 & 0.20 & 1 \\
\hline & Early weaning & -29.35 & 0.1 & 421.12 & $0.000^{*}$ & -63.80 & $0.000^{*}$ \\
\hline \multirow{4}{*}{ Aged-phase } & Late weaning & -55.77 & $0.000^{*}$ & 359.44 & $0.000^{*}$ & -9.20 & $0.000^{*}$ \\
\hline & Pre-pubertal & -57.35 & $0.000^{*}$ & -179.276 & $0.001^{*}$ & -18.80 & $0.000^{*}$ \\
\hline & Adolescent & -148.47 & $0.000^{*}$ & -760.20 & $0.000^{*}$ & 0.40 & 1 \\
\hline & Adulthood & -9.89 & 1 & 110.08 & 0.1 & -0.20 & 1 \\
\hline
\end{tabular}

* = Statistically significant

Table 4: Comparison between the means of the average area of the epidermal thickness, dermal thickness and number of the hair follicles of the different studied groups.

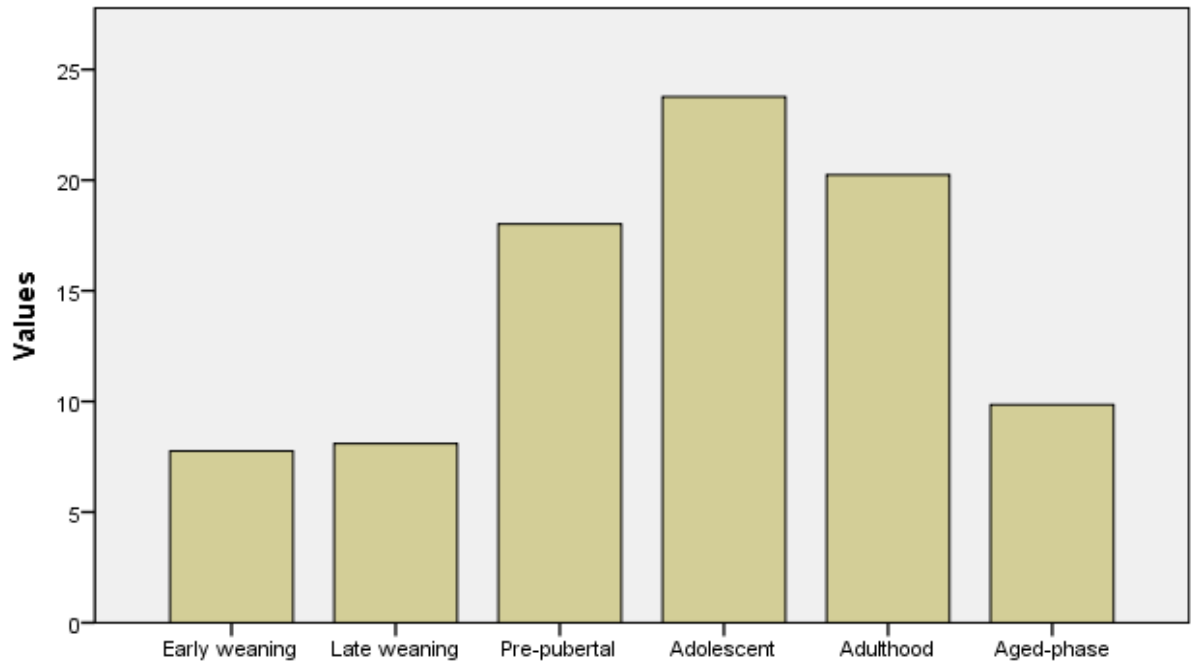

Age groups

Figure 10: The mean area of the collagen of the different studied groups. 


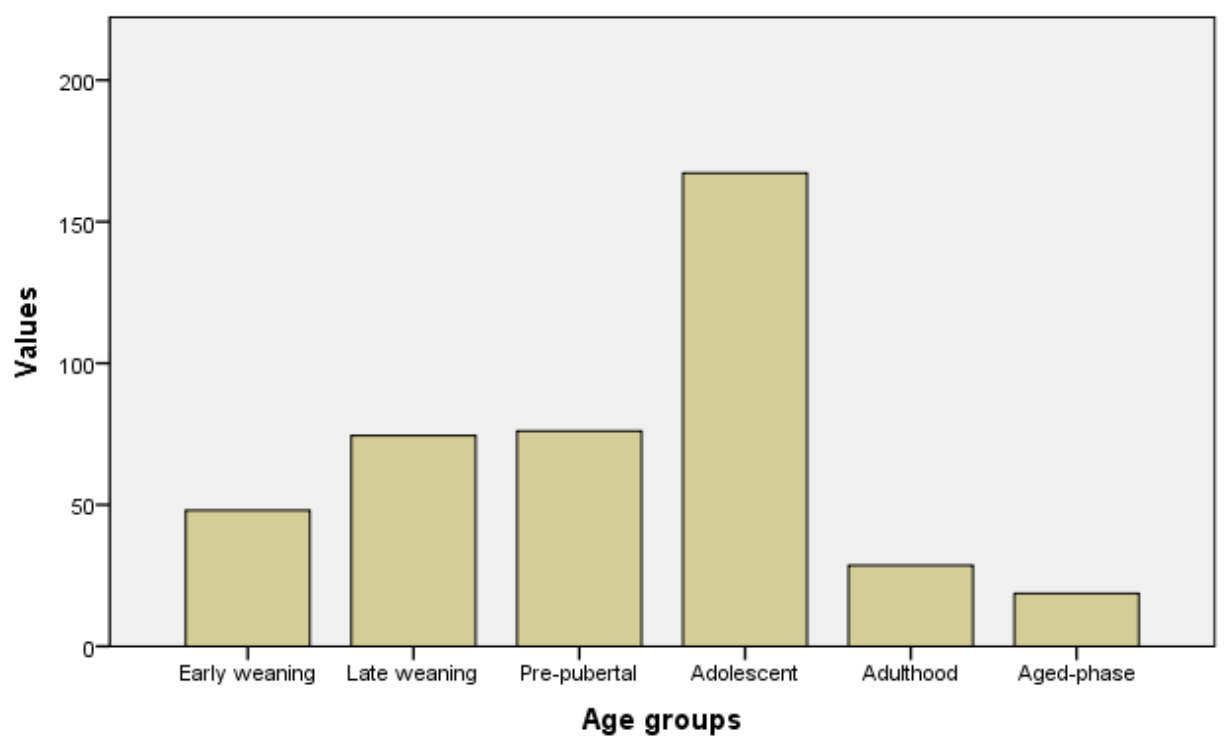

Figure 11: The mean of the epidermal thickness $(\mu)$ of the different studied groups

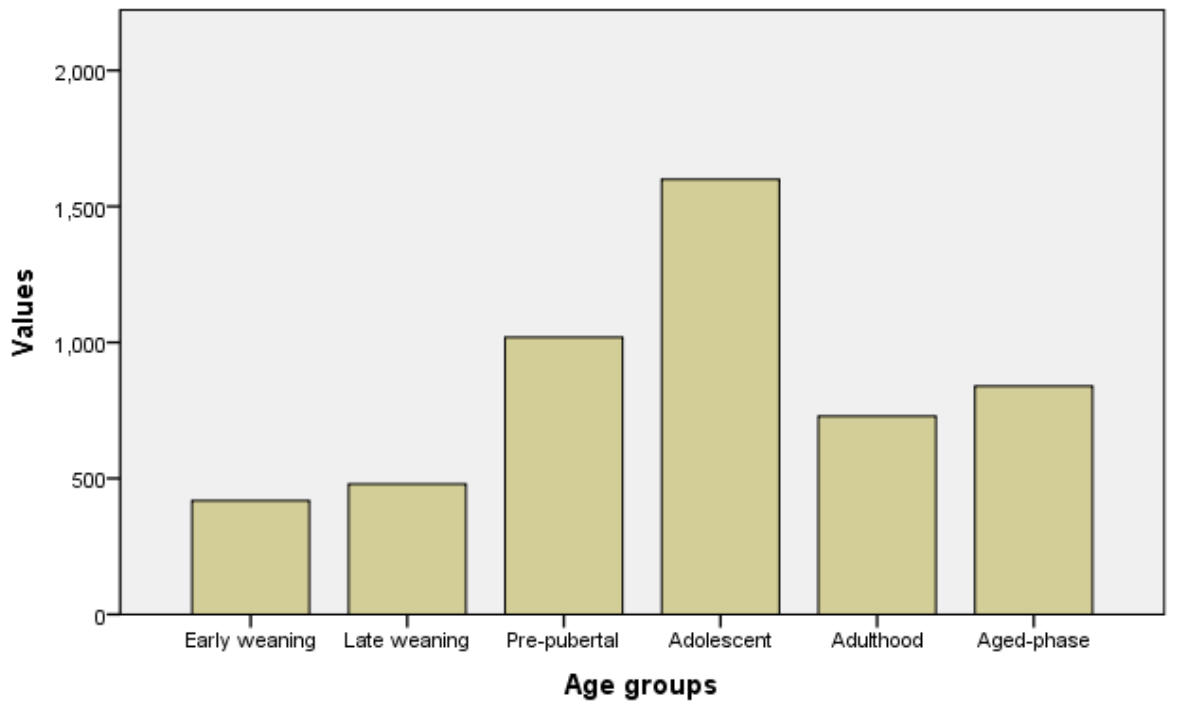

Figure 12: The mean of the dermal thickness $(\mu)$ of the different studied groups groups

and vascular networks, epidermal derived appendages, fibroblasts, macrophages and mast cells. Elastic and collagen tissue are the main types of fibrous connective tissue [15].

The epidermal thickness increased steadily in the late weaning, pre-pubertal and adolescent groups, after that the epidermal thickness decreased in the adulthood and aged-phase groups. The later decrease in the thickness was mostly due to the decrease in epidermal cell size observed in these age groups [7]. Despite the overall thinning of the epidermis in the adulthood and aged-phase groups in the current study, no morphological evidence that the protective function of the skin was compromised. Concerning the adulthood and aged-phase groups in humans, there were conflicting data regarding the epidermal thinning [8]. An increase in thickness of the epidermis was observed in younger and older volunteers in one study [4]; in another study, ageing revealed a slight but significant decrease in epidermal thickness in ageing volunteers [5]. Thinner and flattened epidermis, along with impaired synthesis of cytokines or cell-to-cell signals in response to environmental stress, may result in impaired wound healing and impaired the formation of surgical scars in aged human individuals [6].

The stratum corneum cells were clearly seen in the weaning, pre-pubertal and adolescent groups, but were seen with difficulty in the adulthood and aged-phase groups. In the latter group, they were 


\begin{tabular}{|c|c|c|c|c|c|c|c|}
\hline \multirow{2}{*}{ (I) Age group } & \multirow{2}{*}{ (J) Age group } & \multicolumn{2}{|c|}{$\begin{array}{l}\text { Number of } \\
\text { sebaceous glands/field }\end{array}$} & \multicolumn{2}{|l|}{$\begin{array}{l}\text { Average area of } \\
\text { collagen fibres }\end{array}$} & \multicolumn{2}{|l|}{$\begin{array}{l}\text { Optic density of } \\
\text { elastic fibres }\end{array}$} \\
\hline & & Mean Difference (I-J) & $P$ value & Mean Difference (I-J) & $P$ value & $\begin{array}{l}\text { Mean Difference } \\
(I-J)\end{array}$ & $P$ value \\
\hline \multirow{5}{*}{ Early weaning } & Late weaning & 5.40 & $0.000^{*}$ & -0.34 & 1 & -0.10 & 1 \\
\hline & Pre-pubertal & 4.20 & $0.001^{*}$ & -10.26 & .054 & 15.48 & $0.000^{*}$ \\
\hline & Adolescent & 4.40 & $0.001^{*}$ & -16.00 & $0.001^{*}$ & 20.54 & $0.000^{*}$ \\
\hline & Adulthood & 5.20 & $0.000^{*}$ & -12.48 & $0.01^{*}$ & 20.97 & $0.000^{*}$ \\
\hline & $2^{\text {nd }}$ year & 5.40 & $0.000^{*}$ & -2.09 & 1 & 20.86 & $0.000^{*}$ \\
\hline \multirow{5}{*}{$\begin{array}{l}\text { Late } \\
\text { weaning }\end{array}$} & Early weaning & -5.40 & $0.000^{*}$ & 0.34 & 1 & 0.10 & 1 \\
\hline & Pre-pubertal & -1.20 & 1 & -9.92 & 0.07 & 15.58 & $0.000^{*}$ \\
\hline & Adolescent & -1.00 & 1 & -15.66 & $0.001^{*}$ & 20.64 & $0.000^{*}$ \\
\hline & Adulthood & -0.20 & 1 & -12.14 & $0.01^{*}$ & 21.07 & $0.000^{*}$ \\
\hline & Aged-phase & 0.00 & 1 & -1.752 & 1 & 20.96 & $0.000^{*}$ \\
\hline \multirow{5}{*}{ Pre-pubertal } & Early weaning & -4.20 & $0.001^{*}$ & 10.26 & 0.054 & -15.48 & $0.000^{*}$ \\
\hline & Late weaning & 1.00 & 1 & 9.92 & 0.07 & -15.58 & $0.000^{*}$ \\
\hline & Adolescent & 0.20 & 1 & -5.74 & 1 & 5.06 & $0.000^{*}$ \\
\hline & Adulthood & 1.00 & 1 & -2.22 & 1 & 5.49 & $0.000^{*}$ \\
\hline & Aged-phase & 1.20 & 1 & 8.17 & 0.2 & 5.38 & $0.000^{*}$ \\
\hline \multirow{6}{*}{ Adolescent } & Early weaning & -4.40 & $0.001^{*}$ & 16.00 & $0.001^{*}$ & -20.54 & $0.000^{*}$ \\
\hline & Late weaning & 1.00 & 1 & 15.66 & $0.001^{*}$ & -20.64 & $0.000^{*}$ \\
\hline & Pre-pubertal & -0.20 & 1 & 5.74 & 1 & -5.06 & $0.000^{*}$ \\
\hline & Adulthood & 0.80 & 1 & 3.52 & 1 & 0.43 & 1 \\
\hline & Aged-phase & 1.00 & 1 & 13.91 & $0.003^{*}$ & 0.32 & 1 \\
\hline & Early weaning & -5.20 & $0.000^{*}$ & 12.48 & $0.01^{*}$ & -20.97 & $0.000^{*}$ \\
\hline \multirow{5}{*}{ Adulthood } & Late weaning & 0.20 & 1 & 12.14 & $0.01^{*}$ & -21.07 & $0.000^{*}$ \\
\hline & Pre-pubertal & -1.00 & 1 & 2.22 & 1 & -5.49 & $0.000^{*}$ \\
\hline & Adolescent & -0.80 & 1 & -3.52 & 1 & -0.43 & 1 \\
\hline & Aged-phase & 0.20 & 1 & 10.39 & $0.04^{*}$ & -0.11 & 1 \\
\hline & Early weaning & -5.40 & $0.000^{*}$ & 2.09 & 1 & -20.86 & $0.000^{*}$ \\
\hline \multirow{4}{*}{ Aged-phase } & Late weaning & 0.00 & 1 & 1.752 & 1 & -20.96 & $0.000^{*}$ \\
\hline & Pre-pubertal & -1.20 & 1 & -8.17 & 0.2 & -5.38 & $0.000^{*}$ \\
\hline & Adolescent & -1.00 & 1 & -13.91 & $0.003^{*}$ & -0.32 & 1 \\
\hline & Adulthood & -0.20 & 1 & -10.39 & $0.04^{*}$ & 0.11 & 1 \\
\hline
\end{tabular}

Table 5: Comparison between the means of the number of sebaceous glands, average area of collagen fibres and optic density of elastic fibres of the different studied groups.

seen only by using the electron microscopy. These cells are the most differentiated cells in the skin. They are coated from the outside with an extracellular layer of lipids that form the major constituent of the water barrier in the epidermis. In addition, they protect the body from the outside detrimental influences [16]. The presence of the stratum corneum cells, in the current study, with their intracellular spaces filled with electron-dense materials provide structural evidence that the barrier ability is not compromised in senile skin.

The stratum granulosum cells were identified in all age groups in the current study and they were not affected by the ageing process. They contain the keratohyalin granules which contain the two major intermediate filament-associated proteins, filaggrin and trichohyalin. The keratohyalin granules and filaggrin are markers of epidermal differentiation [17].

The stratum basale cells were also identified in all age groups in the current study and they were not affected by the ageing process. The basal cells are attached to the basal lamina via hemidesmosomes. The hemidesmosomes are involved in promoting the adhesion of epithelial cells to the underlying basement membrane [18]. In the current study, the hemidesmosomes of the adulthood and aged-phase groups exhibited intracellular attachment plaques on the cytoplasmic side of the basal plasma membranes. Absence or defects of hemidesmosomal proteins result in devastating blistering diseases of the skin [18].
The neighboring stratum basale cells and stratum spinosum cells are attached to each other's via desmosomes. Desmosomes are intercellular adhering junctions serving to attach cells to each other [19]. Autoantibodies in patients suffering from the autoimmune blistering skin diseases are directed to $\mathrm{Ca}^{++}$-sensitive cell surface proteins within desmosomes [19]. Neither the desmosomes nor hemidesmosomes have been affected by the ageing process in the current study.

A relatively flattening of the dermal-epidermal junction was observed in the adulthood and aged-phase groups in the current study. This flattening results in a more fragile tissue that is less resistant to shearing forces [20]. Similarly in the human, flattening of the d dermalepidermal junction was seen in the elderly individuals [21].

In the current study, the dermal thickness and the mean area of collagen were correlated to each other as the collagen makes up $70-80 \%$ of the dry weight of the skin [22].

The collagen fibres were found in the current study in the papillary and reticular layers of the dermis and they give the dermis its mechanical and structural integrity [22]. The collagen fibres in the papillary layer were thin and form a network of fibres which probably plays a role in maintaining a specific arrangement of the collagen fibres in the skin [23]. The collagen fibres in the reticular layer arranged in the form of bundles as when the skin is subjected to tension, the collagen bundles 
Citation: Zaki SM (2015) Characteristics of the Skin of the Female Albino Rats in Different Ages: Histological, Morphometric and Electron Microscopic Study. J Cytol Histol S3:004. doi:10.4172/2157-7099.S3-004

appear in a direction parallel to the direction of the applied tension [24]. These bundles were distributed in the current work parallel and perpendicular to the surface epithelial. This way of arrangement allows continual movements of the collagen fibres to absorb the minor stresses of normal activity and relies on the ultimate strength of collagen to resist severe stretch [25].

The elastin is a minor component of the dermis, but it has an important function in providing the elasticity of the skin [15]. A negative linear effect of the age on the optic density of elastic fibres was observed in the current study $\left(\mathrm{R}^{2}=0.80, \mathrm{P}=0.000\right)$, so $80 \%$ of the reduction of elastic fibres could be explained by the effect of ageing process.

The connective tissue sheath, external root sheath and internal root sheath were seen in the early weaning group in the current study indicating the follicle maturation, but the hair follicle morphogenesis is completed around postnatal day 14 [26].

The hair follicles occupied mainly the deep part of the dermis in the late weaning, pre-pubertal and adolescent groups. The deep position of the hair follicles is related to the anagen (growth) phase of the hair growth cycles [27]. In the adulthood and aged-phase groups the hair follicles changed their position, shallower and occupied higher position in the dermis. This higher position is related to the catagen (regression) and telogen (quiescence) phases of the hair growth cycles. The hair follicles became shallower towards regression (catagen) phase, and became constantly shallow during the quiescence (telogen) phase [27].

A negative linear effect of the age on the number of hair follicles was observed in the current study $\left(\mathrm{R}^{2}=0.60, \mathrm{P}=0.000\right)$, so $60 \%$ of the reduction number of hair follicles could be explained by the effect of ageing process. The decreased formation of the hair follicles was secondary to the decreased number of dermal cells as the number of dermal cells is critical for the formation of the hair follicles [28]. Similarly, a decline in hair number, rate of growth, and diameter had been documented with progressive ageing in human [21].

The sebaceous glands changes were remarkably similar to the hair follicles changes concerning their depth at different age groups. No morphological change was observed in the glands with ageing in the current study. A negative linear effect of the age on the number of sebaceous glands was observed in the current study $\left(\mathrm{R}^{2}=0.32, \mathrm{P}=0.001\right)$, so $32 \%$ of the reduction number of sebaceous glands could be explained by the effect of ageing process.

Normal dermal mast cells filled with granules and fibroblasts were seen at different age groups. Fibroblasts and mast cells are regular residents of the dermis. Fibroblasts are responsible for the synthesis and the degradation of fibrous and non-fibrous connective tissue matrix proteins. Mast cells are responsible for IgE mediated acute, subacute and chronic inflammation. These cells are involved in coagulation, wound healing and tissue remodeling [15].

The hypodermis was underdeveloped in the early weaning group with absence of the fat cells. At the late weaning, pre-pubertal and adolescent groups, the hypodermis became well developed and characterized by the presence of fat cells. The adipocyte formation in the rat hypodermis is an integral phase of hair-follicle development in the rat and is linked with hair-follicle growth and development [29]. Finally, the hypodermis became atrophy in the adulthood and agedphase groups as a part of ageing process.

In conclusion, many structural skin changes were observed in the adulthood and aged-phase groups. The epidermis became thinner and flattened, the dermal-epidermal junction became flat, the dermal thickness decreased and the hair follicles became shallower and occupied higher position. All these changes result in impaired wound healing and impaired the formation of scars.

\section{References}

1. Ganceviciene R, Liakou Al, Theodoridis A, Makrantonaki E, Zouboulis CC (2012) Skin anti-aging strategies. Dermatoendocrinol 4: 308-319.

2. Yaar M, Gilchrest BA (2001) Ageing and photoageing of keratinocytes and melanocytes. Clin Exp Dermatol 26: 583-591.

3. Branchet MC, Boisnic S, Frances C, Robert AM (1990) Skin thickness changes in normal aging skin. Gerontology 36: 28-35.

4. Sauermann K, Clemann S, Jaspers S, Gambichler T, Altmeyer P, et al. (2002) Age related changes of human skin investigated with histometric measurements by confocal laser scanning microscopy in vivo. Skin Res Technol. 8: 52-56.

5. Batisse D, Bazin R, Baldeweck T, Querleux B, Lévêque JL (2002) Influence of age on the wrinkling capacities of skin. Skin Res Technol 8: 148-154.

6. Bhattacharyya TK, Thomas JR (2004) Histomorphologic changes in aging skin: observations in the CBA mouse model. Arch Facial Plast Surg 6: 21-25.

7. Argyris TS (1983) The effect of aging on epidermal mass in Balb/c female mice. Mech Ageing Dev 22: 347-354.

8. Thomas DR (2001) Age-related changes in wound healing. Drugs Aging 18 607-620.

9. Kahana T, Birkby WH, Goldin L, Hiss J (2003) Estimation of age in adolescents --the basilar synchondrosis. J Forensic Sci 48: 504-508.

10. Sengupta P (2013) The Laboratory Rat: Relating Its Age With Human's. Int J Prev Med 4: 624-630.

11. Quinn R (2005) Comparing rat's to human's age: how old is my rat in people years? Nutrition 21: 775-777.

12. Lewis EM, Barnett JF Jr, Freshwater L, Hoberman AM, Christian MS (2002) Sexual maturation data for Crl Sprague-Dawley rats: criteria and confounding factors. Drug Chem Toxicol 25: 437-458.

13. Pérez-Alcalá I, Sievert LL, Obermeyer CM, Reher DS (2013) Cross cultura analysis of factors associated with age at natural menopause among latinamerican immigrants to madrid and their spanish neighbors. Am J Hum Biol

14. Andreollo NA, Santos EF, Araújo MR, Lopes LR (2012) Rat's age versus human's age: what is the relationship? Arq Bras Cir Dig 25: 49-51.

15. Prost-Squarcioni C, Fraitag S, Heller M, Boehm N (2008) [Functional histology of dermis]. Ann Dermatol Venereol 135: 1S5-20.

16. Niessen CM (2007) Tight junctions/adherens junctions: basic structure and function. J Invest Dermatol 127: 2525-2532

17. Contet-Audonneau JL, Jeanmaire C, Pauly G (1999) A histological study of human wrinkle structures: comparison between sun-exposed areas of the face with or without wrinkles, and sun-protected areas. Br J Dermatol 140: 10381047.

18. Borradori L, Sonnenberg A (1999) Structure and function of hemidesmosomes: more than simple adhesion complexes. J Invest Dermatol 112: 411-418.

19. Waschke J (2008) The desmosome and pemphigus. Histochem Cell Biol 130: 21-54

20. Lavker RM, Zheng PS, Dong G (1989) Morphology of aged skin. Clin Geriatr Med 5: 53-67.

21. Kurban RS, Bhawan J (1990) Histologic changes in skin associated with aging J Dermatol Surg Oncol 16: 908-914

22. Oikarinen A (1994) Aging of the skin connective tissue: how to measure the biochemical and mechanical properties of aging dermis. Photodermatol Photoimmunol Photomed 10: 47-52.

23. Ushiki T (2002) Collagen fibers, reticular fibers and elastic fibers. A comprehensive understanding from a morphological viewpoint. Arch Histo 
Citation: Zaki SM (2015) Characteristics of the Skin of the Female Albino Rats in Different Ages: Histological, Morphometric and Electron Microscopic Study. J Cytol Histol S3:004. doi:10.4172/2157-7099.S3-004

Cytol 65: 109-126.

24. Sakai S, Yamanari M, Lim Y, Nakagawa N, Yasuno Y (2011) In vivo evaluation of human skin anisotropy by polarization-sensitive optical coherence tomography. Biomed Opt Express 2: 2623-2631.

25. Ribeiro JF, dos Anjos EH, Mello ML, de Campos Vidal B (2013) Skin collagen fiber molecular order: a pattern of distributional fiber orientation as assessed by optical anisotropy and image analysis. PLoS One 8: e54724.

26. Müller-Röver S, Handjiski B, van der Veen C, Eichmüller S, Foitzik K, et al. (2001) A comprehensive guide for the accurate classification of murine hair follicles in distinct hair cycle stages. J Invest Dermatol 117: 3-15.
27. Paus R, Müller-Röver S, Van Der Veen C, Maurer M, Eichmüller S, et al. (1999) A comprehensive guide for the recognition and classification of distinct stages of hair follicle morphogenesis. J Invest Dermatol 113: 523-532.

28. Park KC, Choi HR, Na JI, Cho HJ, Nam KM, et al. (2012) Effects of murine dermal cells on the regulation of hair growth is dependent on the cell number and post-natal age of newborn mice. Ann Dermatol 24: 94-98.

29. Hausman GJ, Campion DR, Richardson RL, Martin RJ (1981) Adipocyte development in the rat hypodermis. Am J Anat 161: 85-100. 